\title{
Experimental study on the vibration of an overhung rotor with a propagating transverse crack
}

\author{
S.A. Adewusi and B.O. Al-Bedoor \\ Mechanical Engineering Department, King Fahd University of Petroleum and Minerals, P. O. Box 841, Dhahran \\ 31261, Saudi Arabia
}

Received 7 June 2000

Revised 30 July 2001

\begin{abstract}
This paper presents an experimental study on the dynamic response of an overhung rotor with a propagating transverse crack. The effects of a propagating transverse crack and side load on the dynamic response of an overhung rotor are investigated in order to identify vibration signatures of a propagating crack in rotating shafts. Startup and steady state vibration signatures were analyzed and presented in the form of Bode plots, Frequency Spectrum Cascades, Frequency Spectrum Waterfalls and orbits. The startup results showed that crack reduces the critical speed and increases the vibration amplitude of the rotor system. It also excites $2 \mathrm{X}$ vibration in the startup vibration signatures. The steady state results showed that the propagating crack produces changes in vibration amplitudes of $1 \mathrm{X}$ and $2 \mathrm{X}$ vibration harmonics and excites $3 \mathrm{X}$ harmonic just before fracture. During crack propagation, $1 \mathrm{X}$ amplitude may increase or decrease depending on the location of the crack and the direction of vibration measurement while $2 \mathrm{X}$ amplitude always increases. The steady state vibration signal of a propagating crack also produces a two-loop orbit.
\end{abstract}

\section{Introduction}

The overhung rotor is important as it can be found in many industrial turbo-machines in which the compressor and turbine has a single shaft, for an example, the turbocharger. Lateral forces can develop as a result of misalignment, rotor weight, and fluid force in fluid handling machines and are usually in large scale than the unbalance force. Although rotors are carefully designed for fatigue loading and high level of safety by using high quality materials and precise manufacturing techniques, catastrophic failures of rotors as a result of cracks may still occur. Particularly, in high speed rotating machines, in which the rotor is carrying disks, blades, gears, etc which are of considerable weight. Continuous operation of a cracked rotor will result in crack propagation, which may result in a sudden breakdown of the machine or one of its elements if not detected at an early stage. Although there are some reported effects of crack on vibration signals, little in- formation is found on the effect of a propagating crack on vibration signals; this is the purpose of this work.

Due to the danger that the presence of a crack in rotor poses, research has been geared-up towards the detection of crack in rotating machines using vibration signals. Many researchers [1-16] have modeled and studied the dynamic response of cracked rotors using different approaches. Some used only theoretical modeling method, others combined both theoretical and experimental methods and few used only experimental method. Gasch [1] studied the stability behavior of the De-Laval rotor due to a crack and imbalance. His results showed that the recognition of cracks is very difficult because the significant double and triple frequency vibrations are only very slightly involved in the crack response. Grabowski [2] used modal analysis to study the vibration behavior of a turbine rotor containing a transverse crack. He reported that the crack excites $1 \mathrm{X}$ and $2 \mathrm{X}$ vibrations, which are independent of the out-of-balance but depend on the crack loca- 


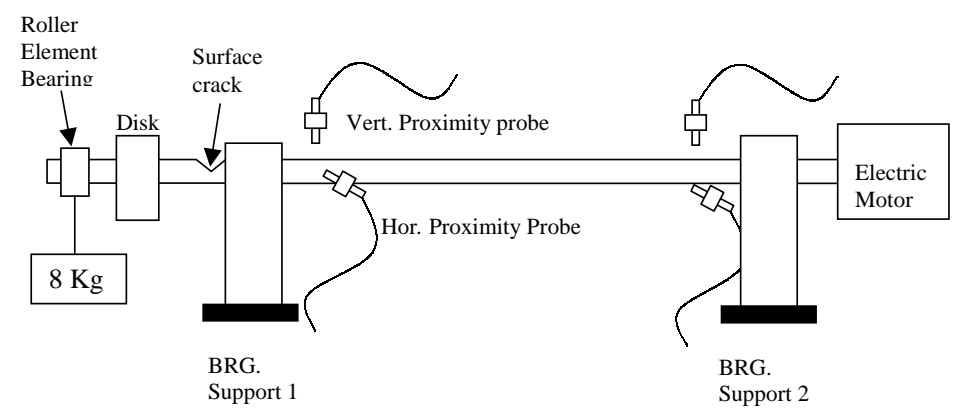

(a)

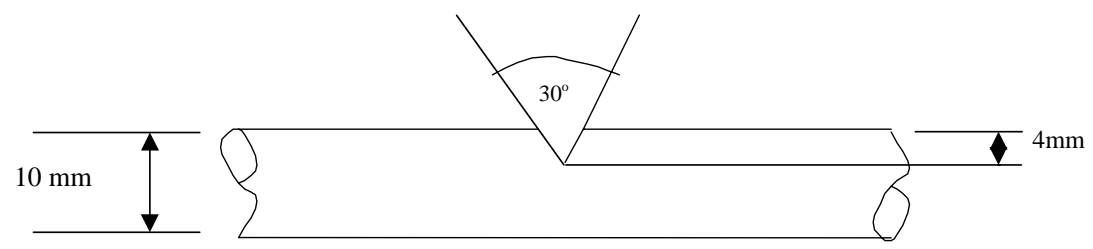

(b)

Fig. 1. Experiment rig. (a) Schematic diagram for Overhung rotor arrangement. (b) Crack geometry.

Table 1

Summary of the experimental results

\begin{tabular}{|c|c|c|c|c|c|c|}
\hline \multirow[t]{3}{*}{ Description } & \multicolumn{4}{|c|}{ Steady state } & \multirow{2}{*}{\multicolumn{2}{|c|}{$\frac{\text { Start up }}{\text { Critical speeds (rpm) }}$}} \\
\hline & \multicolumn{2}{|c|}{ Y probe } & \multicolumn{2}{|c|}{$\mathrm{X}$ probe } & & \\
\hline & $1 \mathrm{X}(\mathrm{mil})$ & $2 \mathrm{X}$ (mil) & $1 \mathrm{X}(\mathrm{mil})$ & $2 \mathrm{X}$ (mil) & $\mathrm{Y}$ & $\mathrm{X}$ \\
\hline $\begin{array}{l}\text { Un-cracked Shaft with hanging side load } \\
\text { of } 8 \mathrm{~kg}(3500 \mathrm{rpm})\end{array}$ & 2.080 & 0.025 & 0.694 & 0.231 & 4025 & 1785 \\
\hline $\begin{array}{l}\text { 1st Cracked Shaft with } 4 \mathrm{~mm} \text { notch with } \\
\text { hanging side load of } 8 \mathrm{~kg}(3500 \mathrm{rpm})\end{array}$ & $\begin{array}{c}0.617 \\
(-70.3 \%)\end{array}$ & $\begin{array}{c}2.130 \\
\text { (very high) }\end{array}$ & $\begin{array}{c}0.720 \\
(+3.74 \%)\end{array}$ & $\begin{array}{l}2.850 \\
\text { (high) }\end{array}$ & 4010 & 1728 \\
\hline $\begin{array}{l}\text { 2nd Cracked Shaft with } 4 \mathrm{~mm} \text { notch with } \\
\text { hanging side load of } 8 \mathrm{~kg}(3500 \mathrm{rpm})\end{array}$ & $\begin{array}{c}4.990 \\
(+139.9 \%)\end{array}$ & $\begin{array}{l}1.820 \\
\text { (high) }\end{array}$ & $\begin{array}{c}3.140 \\
(+244.6 \%)\end{array}$ & $\begin{array}{c}5.860 \\
\text { (very high) }\end{array}$ & 3750 & 1720 \\
\hline
\end{tabular}

tions. Dimarogonas and Paipetis [3] developed a relationship between crack depth and rotor local flexibility. Imam et al. [4] used a 3-D finite element method and a nonlinear rotor dynamics to model a cracked rotor system and developed an on-line rotor crack detection and monitoring system. Histogram signature analysis, which is the FFT of the difference between the averaged vibration signals of cracked and un-cracked shaft was used. Experiment results showed $1 \mathrm{X}$ and $2 \mathrm{X}$ vibration peaks. Inagaki et al. [5] utilized the iterative numerical calculation (transfer matrix) method to analyze transverse vibrations of a general cracked-rotor bearing system and an experiment was used to validate the results. The experimental results showed $1 \mathrm{X}$ and $2 \mathrm{X}$ vibration responses under mutual influences between gravity, imbalance and their phase relations, and vibration mode characteristics at the rotating speed. The work of Dirr and Schmalhorst [6] was comprehensive.
They used vibration measurement method and potential difference method of fatigue crack measurement to study the shape of cracks at different depth during crack propagation in a rotating shaft. The FFT of experimental vibration signals showed $1 \mathrm{X}$ and $2 \mathrm{X}$. 3D Finite Element crack model was also used to study the bending stress distribution near the crack tip. Mayes and Davies [7] analyzed the response of a multi-rotorbearing system with a transverse crack using a linear rotor dynamic computer program. The results were supported by experimental work using a test rig to study the effect of dynamic bending moments and rotor running speed on crack depth. Bently and Bosmans [8] used experimental set-up to study a cracked rotor model of a Reactor Coolant Pump using an overhung rotor. The results showed variations in the amplitude of the $2 \mathrm{X}$ vibration and an orbit with two loops due to crack propagation. Wauer $[9,10]$ carried out a comprehensive 


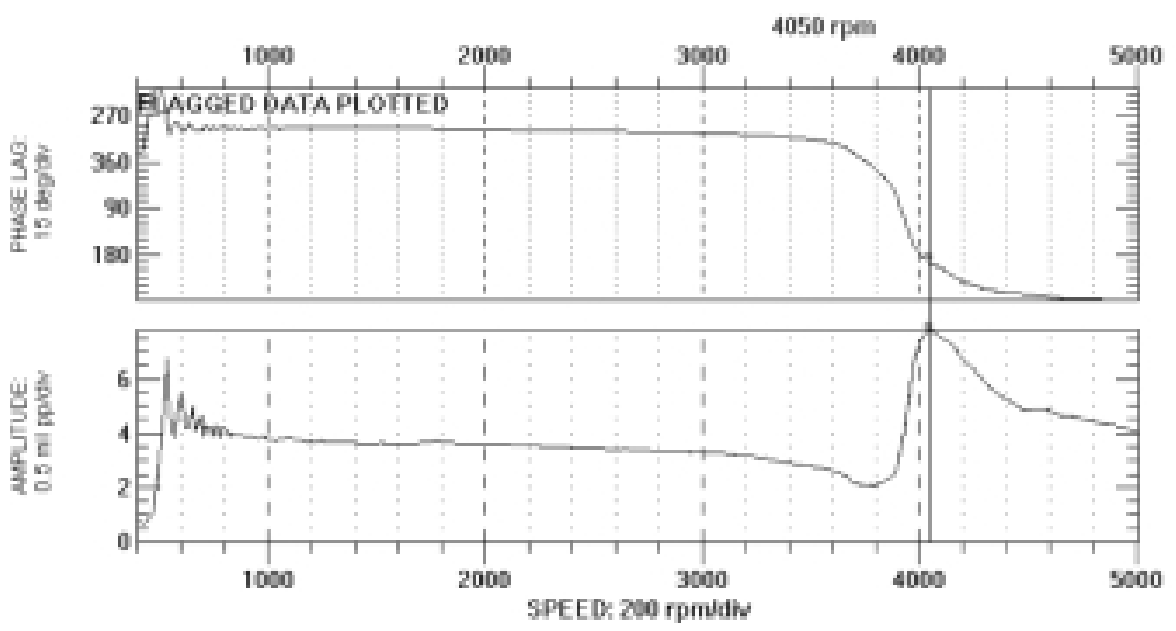

(a) Vertical direction

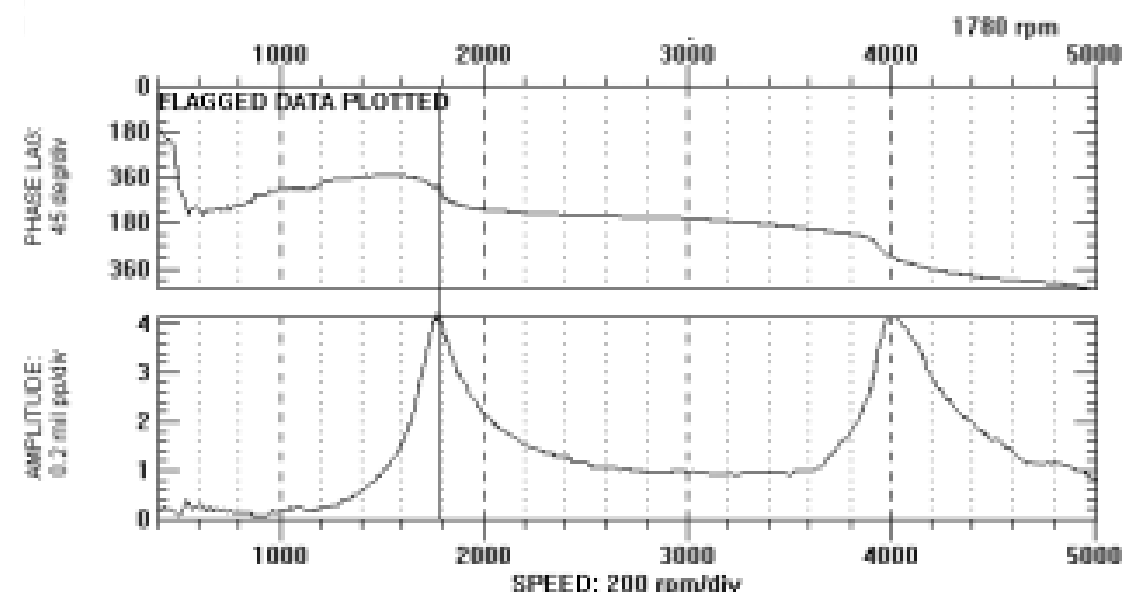

(b) Horizontal direction

Fig. 2. Bode plots of startup data for un-cracked shaft with $8 \mathrm{~kg}$ vertical hanging side load.

literature survey on the state-of-the-art of the dynamics of cracked rotors. He also modeled and formulated the governing dynamic equations of a cracked Timoshenko rotor, which is flexible in extension and torsion. He used the Galerkin's method to reduce the equations of motion. The torsional vibration of a circular shaft with a circumferential crack was studied. Collins et al. [11] studied a cracked Timoshenko rotor by solving the sixcoupled equations obtained by Wauer $[9,10]$. The frequency spectrum of the rotor response to a periodic axial impulse was also studied. The results showed an increase in the coupling between axial, torsional and transverse vibration. Theoretical and experimental study of the on-line crack detection for turbo-generator rotors was presented by Diana et al. [12]. The effects of thermal gradient were accounted for in the diagnos- tic program, using probability evaluation. The difference between the current vibration and the previous vibration was used to calculate the vibration forces. $1 \mathrm{X}$ and $2 \mathrm{X}$ vibration frequency components were reported. Dimarogonas and Papadopoulas [13] studied the stability of cracked rotors in the coupled vibration mode. The frequency spectra of the vibration signal of a 300 MW steam turbine showed high $2 \mathrm{X}, 1 / 2 \mathrm{X}$ and $1 / 4 \mathrm{X}$ vibration components that suggested the existence of deep crack. Meng and Hahn [14] analyzed a cracked Jeffcott rotor theoretically and numerically. WU and Huang [15] studied the dynamic response of a rotor with a transverse crack by numerically solving the dynamic equations of a cracked rotor model. FFT of the response at various speeds, crack depths and crack locations showed $1 \mathrm{X}$ and $2 \mathrm{X}$ harmonics. Floquet theory 


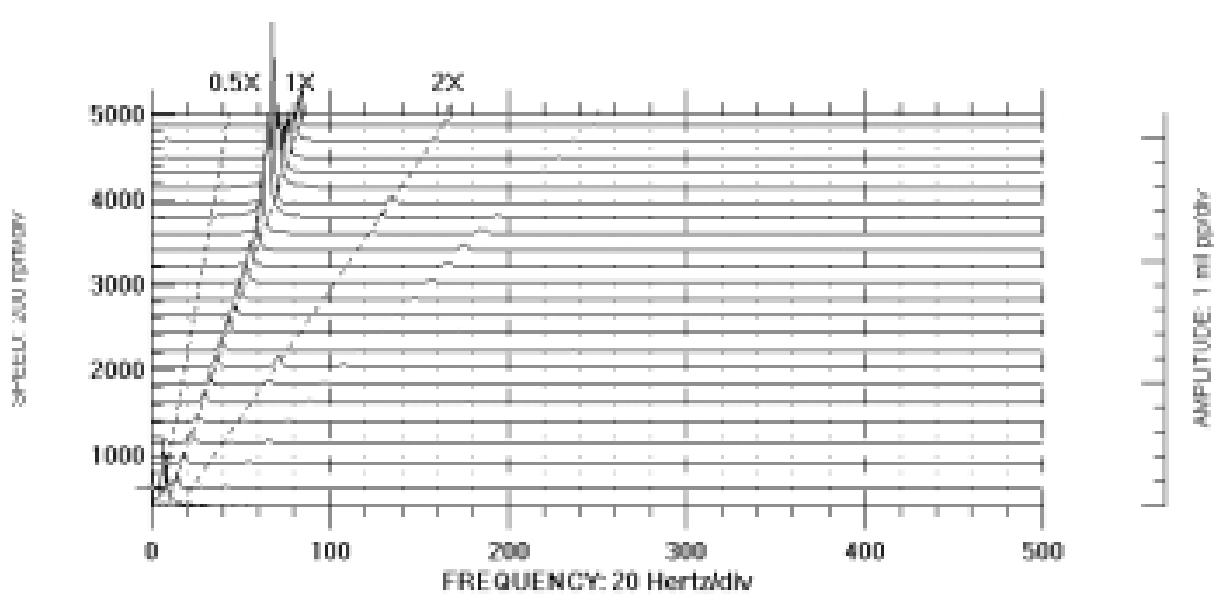

(a) Vertical direction

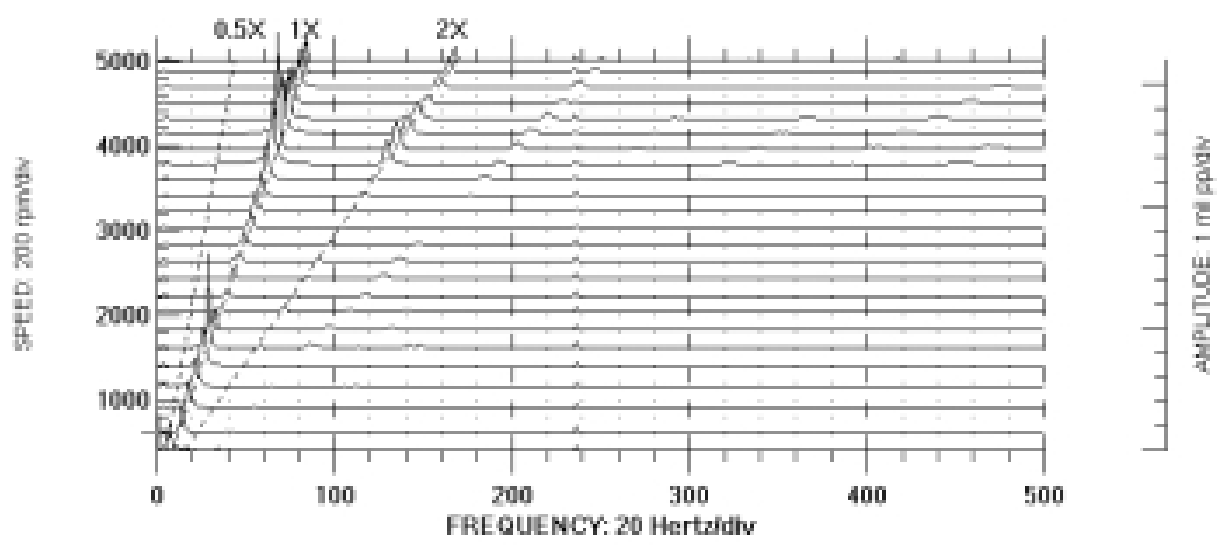

(b) Horizontal direction

Fig. 3. Frequency cascades of the startup data for un-cracked shaft with $8 \mathrm{~kg}$ hanging side load.

and multiple scales methods were also used to study the stability of the cracked shaft system. Zheng [16] numerically studied the vibration of rotor system with a switching crack. He suggested the use of features other than $1 \mathrm{X}$ and $2 \mathrm{X}$ harmonics for crack detection. The Gabor analysis of the vibration signals, after $1 \mathrm{X}$ and $2 \mathrm{X}$ have been removed, showed the presence of transient signals.

Attention has been focused on the study of a simply supported cracked rotor. All the works cited above, with the exception of the work of Bently and Bosmans [8], were on a simply supported rotor. Furthermore, majority of the results showed that crack excites $1 \mathrm{X}$ and $2 \mathrm{X}$ vibration harmonics at steady state. However, imbalance can produce $1 \mathrm{X}$ harmonic while misalignment, asymmetry and looseness of bolts and nuts can also produce $2 \mathrm{X}$ vibration. Similarly, a change in the critical speed of a rotating machine may be caused by other machine faults like looseness and wear. Therefore, in accordance with the suggestion of Zeng [16], more than one vibration feature should be used to characterize the presence of a crack in rotors to avoid wrong diagnosis. This paper uses four different vibration features to study the vibration of an overhung rotor with a transverse propagating crack and side load. These features are Frequency Cascades and Frequency Waterfalls that give information on frequency and time of the vibration signal, Bode plots and orbits.

\section{Experimental setup}

The equipment used for the experiment include a Rotor Kit, Rotor Kit Motor Speed Control, Data Ac- 


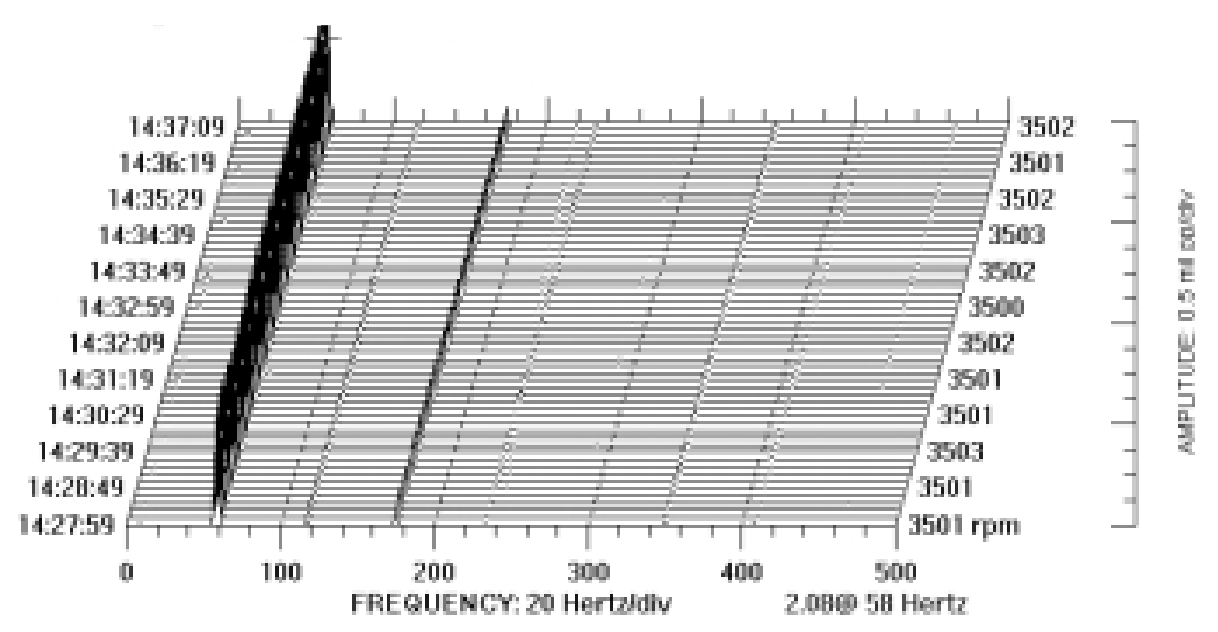

(a) Vertical direction

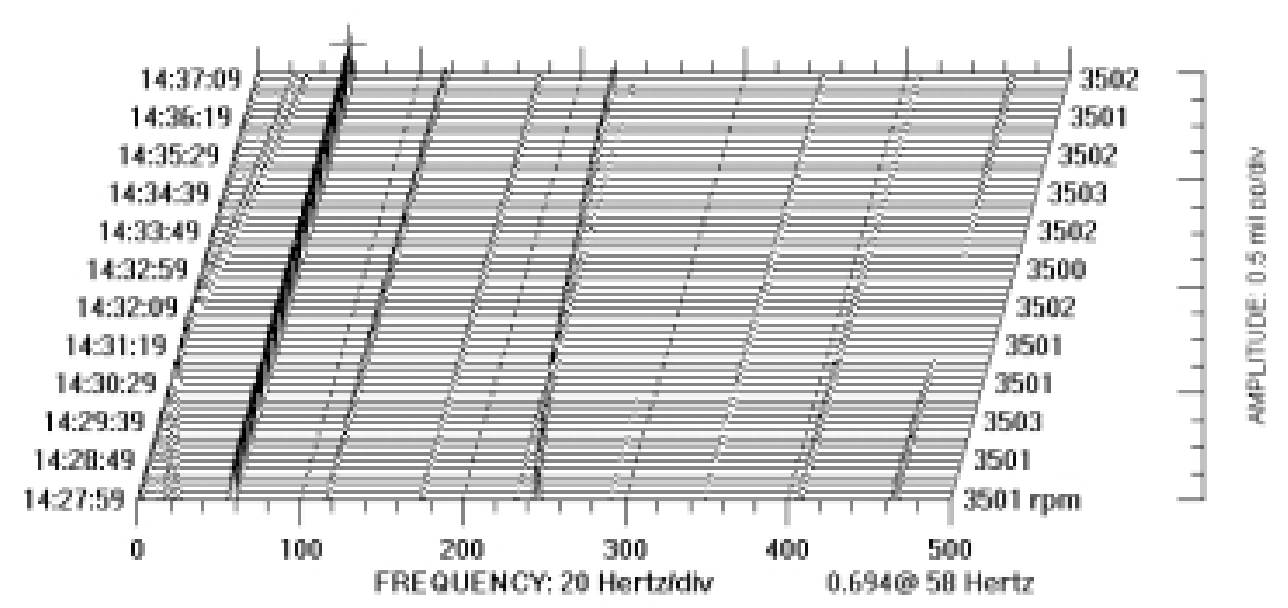

(b) Horizontal direction

Fig. 4. Frequency waterfalls of steady state data for un-cracked shaft with $8 \mathrm{~kg}$ hanging side load.

quisition Interface Unit (DAIU-208P) with accessories, Oscilloscopes, Personal Computer (PC), Eddy Current Displacement/proximity Probes, Automated Diagnostics for Rotating Equipment (ADRE) for Windows Software and shafts. The schematic diagram of the experiment test rig is set up as shown in Fig. 1(a). The proximity probes are fixed on rigid supports $4 \mathrm{~cm}$ from the bearing supports and are connected via auxiliary components to Oscilloscopes to observe the amplitudetime waveforms and orbits of the vibration signals. The probes are also connected to the DAIU-208P, which is in turn connected to the PC. The DAIU operation is controlled by the ADRE for Window Software to collect, store and analyze vibration data to obtain Or- bits, Bode plots, Frequency Spectrum Waterfall, and Frequency Spectrum Cascades.

The shaft material is made of ductile steel bar AISI 4140. The shaft has the following dimensions and properties: $10 \mathrm{~mm}$ diameter, $540 \mathrm{~mm}$ length, mass per unit length of $0.72 \mathrm{~kg} / \mathrm{m}$, Young's Modulus of $200 \mathrm{GPa}$. Two disks each of mass $0.8 \mathrm{~kg}$ and a hanging side load of mass $8 \mathrm{~kg}$ were fitted on the shaft as shown in Fig. 1(a). The $8 \mathrm{~kg}$ hanging side load was applied to produce bending stress on the crack and aid crack propagation. The $8 \mathrm{~kg}$ it is attached to the roller element bearing on the shaft through an inelastic string of diameter $2 \mathrm{~mm}$. The shafts are supported in self-lubricating sleeve bearings. Three shafts are machined one without crack and the other two with $4 \mathrm{~mm}$ depth v-notch 

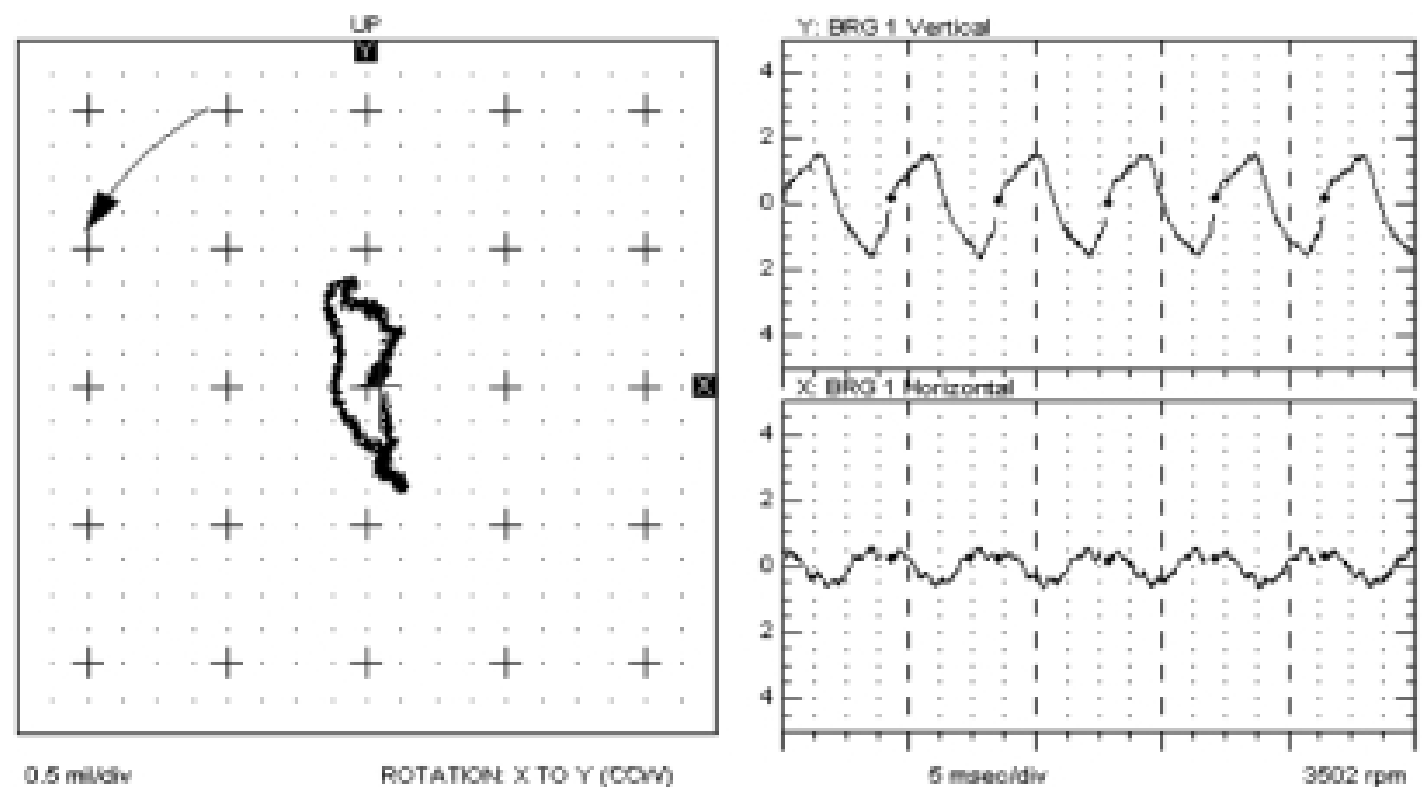

Fig. 5. Orbit for un-cracked shaft with $8 \mathrm{~kg}$ vertical hanging side load.

surface crack. The crack angle is $30^{\circ}$ and the Crack Tip Open Displacement (CTOD) was measured with the optical microscope and was found to be $0.117 \mathrm{~mm}$. Figure 1(b) shows the crack geometry.

Three experiments were carried out. It was ensured that the shaft centerline was perfectly aligned with the Electric Motor rotation axis to eliminate response due to misalignment. The first experiment was for the uncracked shaft with the disks and $8 \mathrm{~kg}$ hanging side load located at $7 \mathrm{~cm}$ and $13 \mathrm{~cm}$ from the Bearing Support 1 , respectively while the distance between the bearing supports was $39 \mathrm{~cm}$. The second experiment consisted of the first cracked shaft with $4 \mathrm{~mm}$ depth v-notch surface crack located at $1.5 \mathrm{~cm}$ from Bearing Support 1 , Fig. 1(a). The locations of the disks, $8 \mathrm{~kg}$ hanging side load, and bearing supports are the same as those for the first experiment. In the third experiment, the second cracked shaft with the $4 \mathrm{~mm}$ depth v-notch surface crack located at $3.5 \mathrm{~cm}$ from the Bearing Support 1 was used. The disks and $8 \mathrm{~kg}$ hanging side load are located at $10 \mathrm{~cm}$ and $16 \mathrm{~cm}$ from the Bearing Support 1 , respectively while the distance between the bearing supports was $39 \mathrm{~cm}$. It should be noted that the $8 \mathrm{~kg}$ side load was attached to the shaft for the three experiments. This enables the effects of a propagating crack to be studied since the effect of the $8 \mathrm{~kg}$ load is common to all set-ups.

The startup and steady vibration signals for each experiment are taken and analyzed and the results are presented and discussed in the following section. The vi- bration signals in both the vertical and horizontal directions measured by the proximity probes located $4 \mathrm{~cm}$ to Bearing Support 1 are considered. The ramp rate for the startup or run-up experiments was $10000 \mathrm{rpm}$ per minute and vibration data are taken every $15 \mathrm{rpm}$ increase in the speed of the rotor. The steady state speed for the steady state experiments was $3500 \mathrm{rpm}$.

\section{Results and discussions}

Startup vibration signals were presented in the form of Bode plots, which give information on the critical speed of the rotor system and Frequency Cascades that give information on the vibration harmonics in the startup signals. Steady state vibration signals were presented in the form of Frequency Waterfalls, which give information on the harmonic components and Bode plots that give information on the movement of the shaft center. The resonance speed corresponding to the critical speed of the rotor system is shown on each Bode plot at the right hand top corner. The vertical overhung side load was attached to the rotor with a thick string (Fig. 1(a)) to aid crack propagation. This arrangement makes the setup to have two degree of freedom in the vertical direction; this is clearly shown in the Bode plots in form of a resonance point at lower speed of $540 \mathrm{rpm}$, in the vertical Bode plots, Figs 2(a) and 6(a). It should be noted that the resonance frequency of the loading system is very small. Therefore at high frequencies 


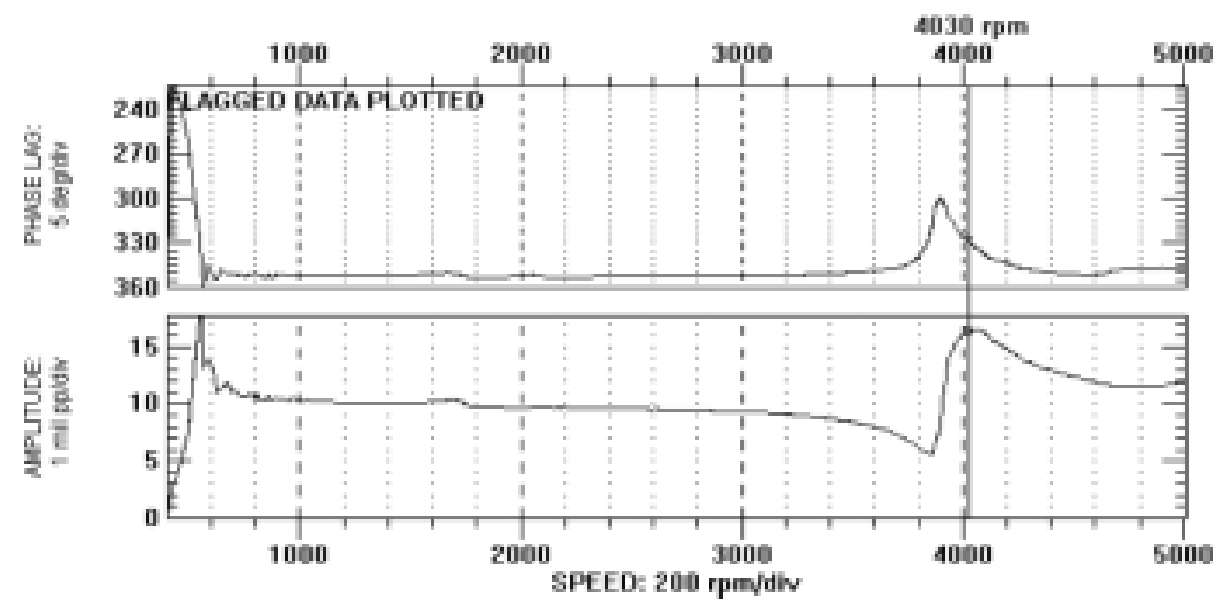

(a) Vertical direction

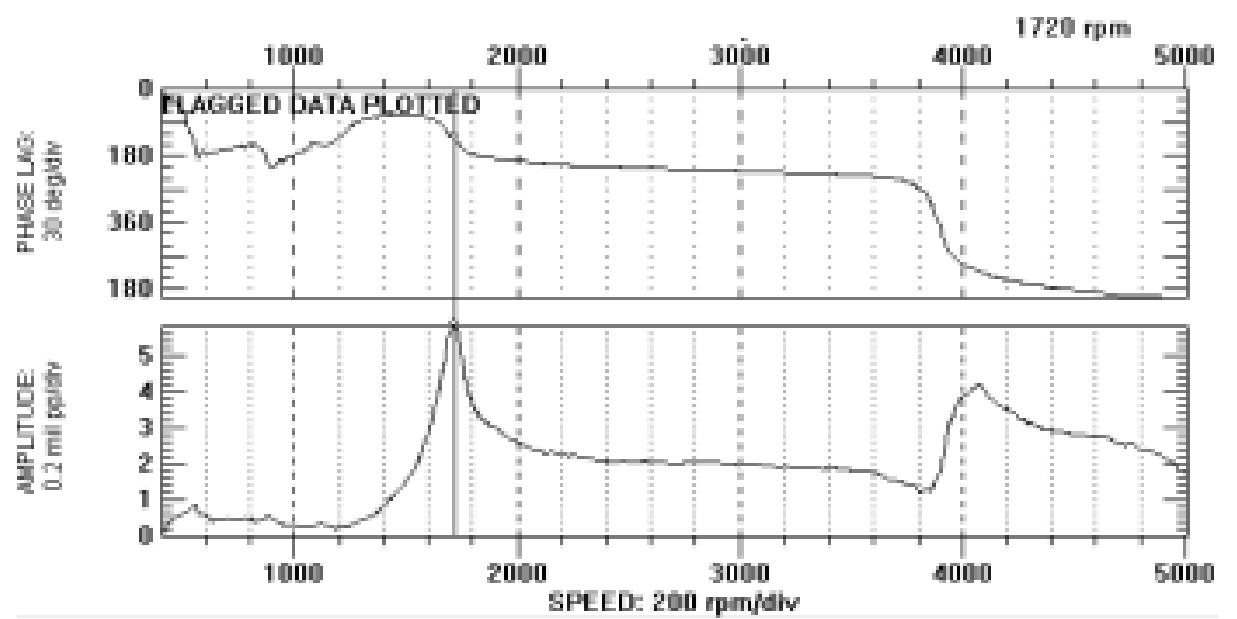

(b) Horizontal direction

Fig. 6. Bode plots of startup data for the $1 \mathrm{st}$ shaft with $4 \mathrm{~mm}$ notch crack and $8 \mathrm{~kg}$ vertical hanging side load.

in order of $3500 \mathrm{rpm}$ (the steady state speed), the $8 \mathrm{~kg}$ mass will not actively participate in the dynamics of the rotor system and can be neglected. This resonance is ignored in the discussion of the results. The amplitude value in mil for $1 \mathrm{X}$ or $2 \mathrm{X}$ vibration harmonic is shown at the down right hand corner of every frequency waterfall. Table 1 summarizes the amplitudes of $1 \mathrm{X}$ and $2 \mathrm{X}$ harmonics for all steady state experiments.

\subsection{Un-cracked shaft}

Figures 2 and 3 represent the startup results for the un-cracked shaft with $8 \mathrm{~kg}$ hanging side load. Figures 2(a) and (b) are Bode plots of the startup vibration signals in the vertical and horizontal directions, respectively. Figure 2(a) shows that the first rotor critical speed in the vertical direction is around $4000 \mathrm{rpm}$ while in the horizontal direction, Fig. 2(b), the first critical speed is around $1800 \mathrm{rpm}$. This asymmetry is due mainly to the side load that stiffens the rotor system in the vertical plane as it forces the shaft to be touching the sleeve bearing at the upper and lower sides continuously. Other important observation in Fig. 2(b) is the second resonance peak, which is probably the rotor second critical speed in the horizontal direction. Figures 3(a) and (b) are the Frequency Cascades of the startup signals in the vertical and horizontal directions, respectively. The horizontal proximity probe shows $2 \mathrm{X}$ vibration harmonics at and above a speed corresponding to the second critical speeds shown in Fig. 2(b). 


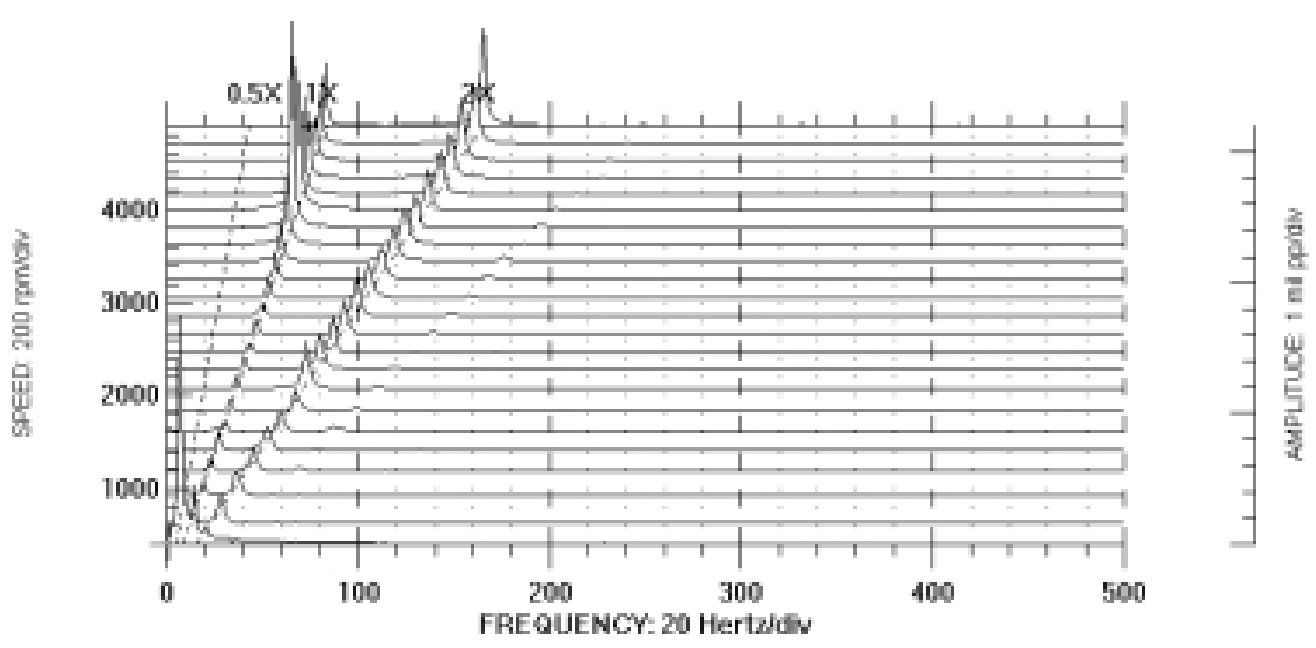

(a) Vertical direction

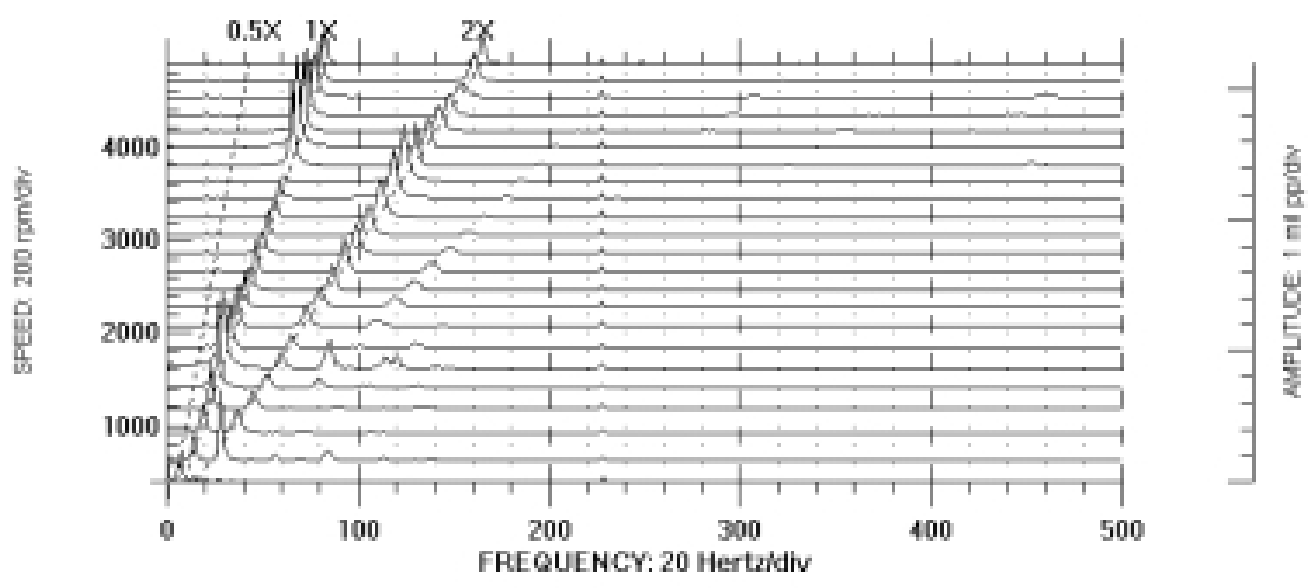

(b) Horizontal direction

Fig. 7. Frequency cascades of startup data for the 1 st shaft with $4 \mathrm{~mm}$ notch crack and $8 \mathrm{~kg}$ vertical hanging side load.

This suggests that the second mode vibration is excited in the horizontal direction with small amplitude compared with the first $1 \mathrm{X}$ vibration. It should be noted that there was no $2 \mathrm{X}$ harmonic in the horizontal direction before the second critical speed was reached.

Figures 4 and 5 present the steady state results for the un-cracked shaft with $8 \mathrm{~kg}$ vertical hanging side load. Figures 4(a) and (b) show the Frequency Waterfall in the vertical and horizontal directions, respectively. Figure 4 shows that the vibration amplitude is greater in the vertical direction with $1 \mathrm{X}$ dominating. $2 \mathrm{X}$ and $3 \mathrm{X}$ vibration harmonics are also present but the amplitude of $3 X$ is greater than that of $2 X$. The vibration in the horizontal direction is rich in harmonics. $1 \mathrm{X}$,
$2 \mathrm{X}, 3 \mathrm{X}, 4 \mathrm{X}$ and higher harmonics are present. There is also an unsteady sub-harmonic in the horizontal signal. The harmonics other than $1 \mathrm{X}$ can be attributed to the effect of the side load, which produced asymmetry in the shaft system. The unsteady behavior shown in Fig. 4(b) was probably due to temperature dependence of the equivalent stiffness and damping characteristics of the bearings. Figure 5 represents the orbit of the steady state signal of the un-cracked shaft and it shows that the movement of the shaft centerline is greater in the vertical direction despite the restriction imposed by the side load. This behavior is due to the fact that the vertical side load increased the static deflection of the shaft in the vertical direction. 


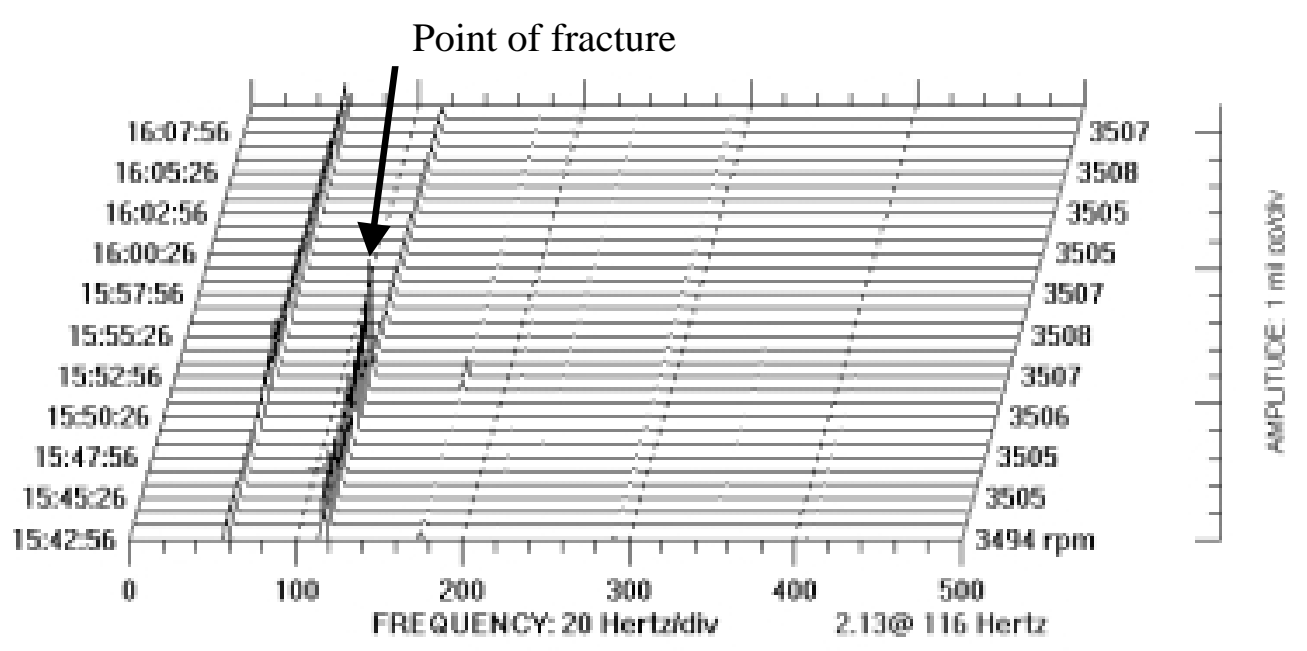

(a) Vertical direction

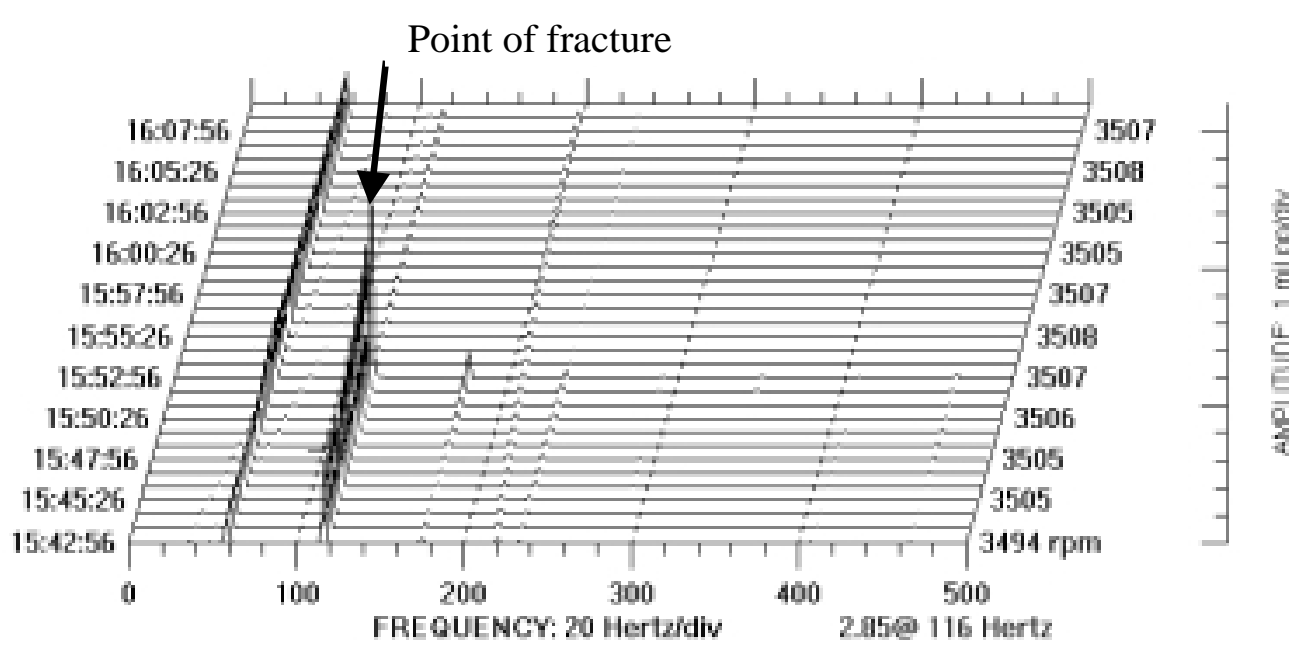

(b) Horizontal direction

Fig. 8. Frequency waterfalls of steady state data for the 1 st shaft with $4 \mathrm{~mm}$ notch crack and $8 \mathrm{~kg}$ vertical hanging side load.

\subsection{Cracked shaft}

Figures 6 and 7 present startup results for the 1st cracked shaft with $4 \mathrm{~mm}$ notch and $8 \mathrm{~kg}$ hanging side load. The startup data for this shaft and the un-cracked shaft were taken more than one time and averaged values of critical speeds are presented in Table 1. The repeated startup experiment for the cracked shaft caused crack propagation and the shaft fractured after some time when left to run at steady state as shown in Fig. 8. Figure 6 shows the Bode plots of startup signals in the vertical and horizontal directions. The crack reduced the critical speed of the rotor system and increased amplitudes of vibration in both directions when Figs 6 and 2 are compared. These results are consistent with the results reported by Dimarogonas and Paipetis [3]. Figure 7 represents the Frequency Cascades of the startup signals in both the vertical and horizontal directions. It can be seen in Fig. 7 that crack excited $2 \mathrm{X}$ vibration harmonic throughout the transient period in both the vertical and horizontal directions unlike what is observed in Fig. 3 where $2 \mathrm{X}$ occurred only in the horizontal direction and at a speed close to and above the second critical speed in the horizontal direction. See 


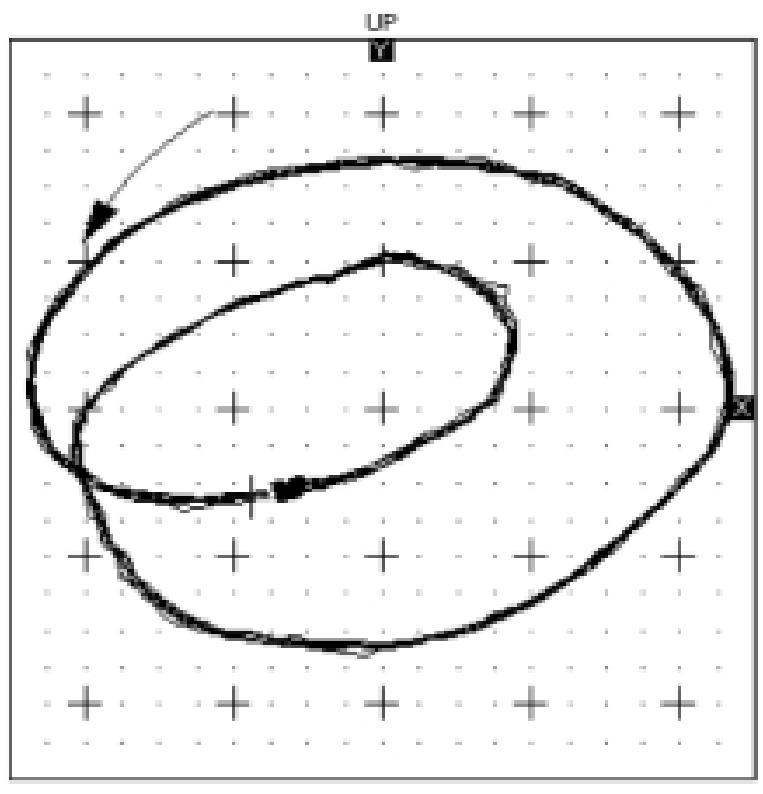

0.5 maldiv

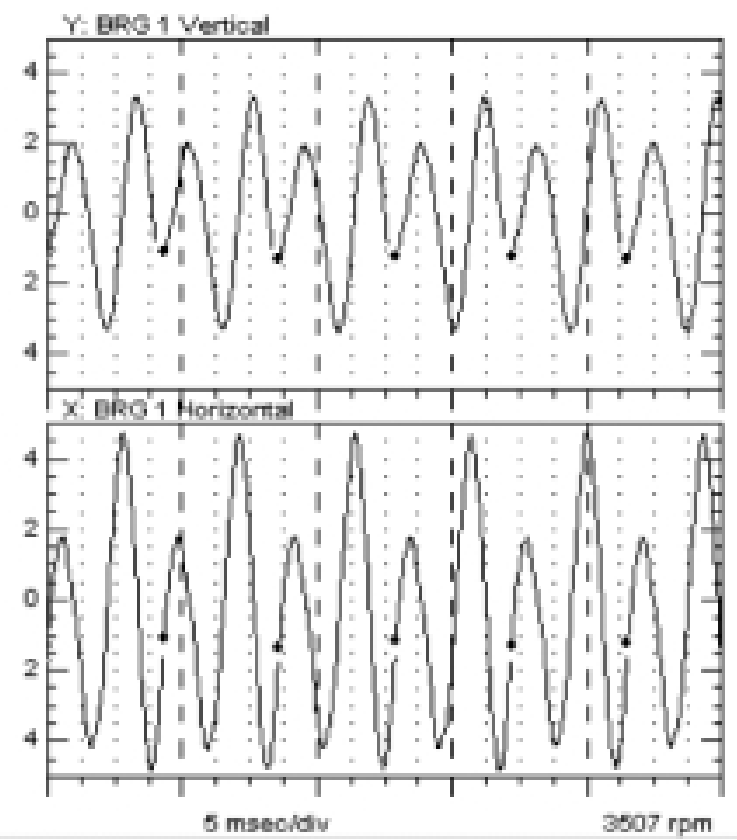

Fig. 9. Orbit of steady state data for the 1st shaft with $4 \mathrm{~mm}$ notch crack and $8 \mathrm{~kg}$ vertical hanging side load before the shaft fractured.

also Fig. 11 for the second cracked shaft. This is an important feature that can be used to identify the presence of crack in rotors in addition to the decrease in critical speed during startup.

Figures 8 and 9 show the steady state results for the 1 st rotor with $4 \mathrm{~mm}$ v-notch crack. Figure 8 is the Frequency Waterfalls for the vertical and horizontal vibration signals during crack propagation and shaft fracture. $1 \mathrm{X}$ and $2 \mathrm{X}$ vibration harmonics are very prominent in both directions. The $2 \mathrm{X}$ amplitude is greater than $1 \mathrm{X}$ amplitude and $2 \mathrm{X}$ amplitude increased as the crack propagated till fracture occurred. This result agrees with the results reported by Gasch [1], Grabowski [2], Imam et al. [4], T. Inagaki et al. [5], G. Dirr and Shmalhorst [6], Davies and Mayes [7] and Diana et al. [12]. A small $3 \mathrm{X}$ vibration harmonic was excited at a later stage of crack propagation just before fracture occurred. Figure 9 represents the orbit of the cracked shaft during crack propagation. Two-loop orbit similar to that reported by Bently and Bosmans [8] is obtained.

Figures 10 and 11 show the startup results for the 2nd rotor with $4 \mathrm{~mm}$ v-notch crack. In this arrangement, the crack, disks and hanging side load were located further away $(10 \mathrm{~cm}$ and $16 \mathrm{~cm}$ respectively) from the Bearing Support 1 than for the 1st cracked rotor $(7 \mathrm{~cm}$ and $13 \mathrm{~cm})$. In this arrangement, the resonance bandwidth as shown in Fig. 10(a) is small compared with Figs 2(a) and 6(b). The decrease in the critical speed and increase in vibration amplitude are greater compared with the 1 st cracked rotor. This is expected since the bending moment due to the hanging side load and disks on the crack is greater than that for the 1st cracked shaft. Gasch [1] and Meng and Hahn [14] have reported that the change in shaft stiffness and dynamic response of a shaft-bearing system depends on both the crack depth and crack location. Figure 11 shows the Frequency Cascades of the 2 nd cracked rotor. $2 \mathrm{X}$ vibration harmonic is present in both directions and is similar to Fig. 6. This shows that crack excites $2 \mathrm{X}$ harmonic during startup.

Figure 12 represents the Frequency Waterfalls of the steady state signals of the 2 nd cracked rotor. $1 \mathrm{X}$ and $2 \mathrm{X}$ harmonics are very prominent, their amplitudes increased as the crack propagated. $1 \mathrm{X}$ amplitude is greater in the vertical direction while $2 \mathrm{X}$ amplitude is greater in the horizontal direction. $3 \mathrm{X}$ vibration harmonic was excited at a later stage of crack propagation. Figure 13 shows the orbit of the steady state vibration signal of the 2 nd cracked rotor, wherein a distorted two-loop orbit is formed. The distortion of the orbit can be attributed to higher wobbling effects of the hanging side load and disks as a result of greater over overhanging length.

Table 1 summarizes the experimental results for the un-cracked and the cracked rotors. The table shows $1 \mathrm{X}$ and $2 \mathrm{X}$ vibration amplitudes measured in the vertical 


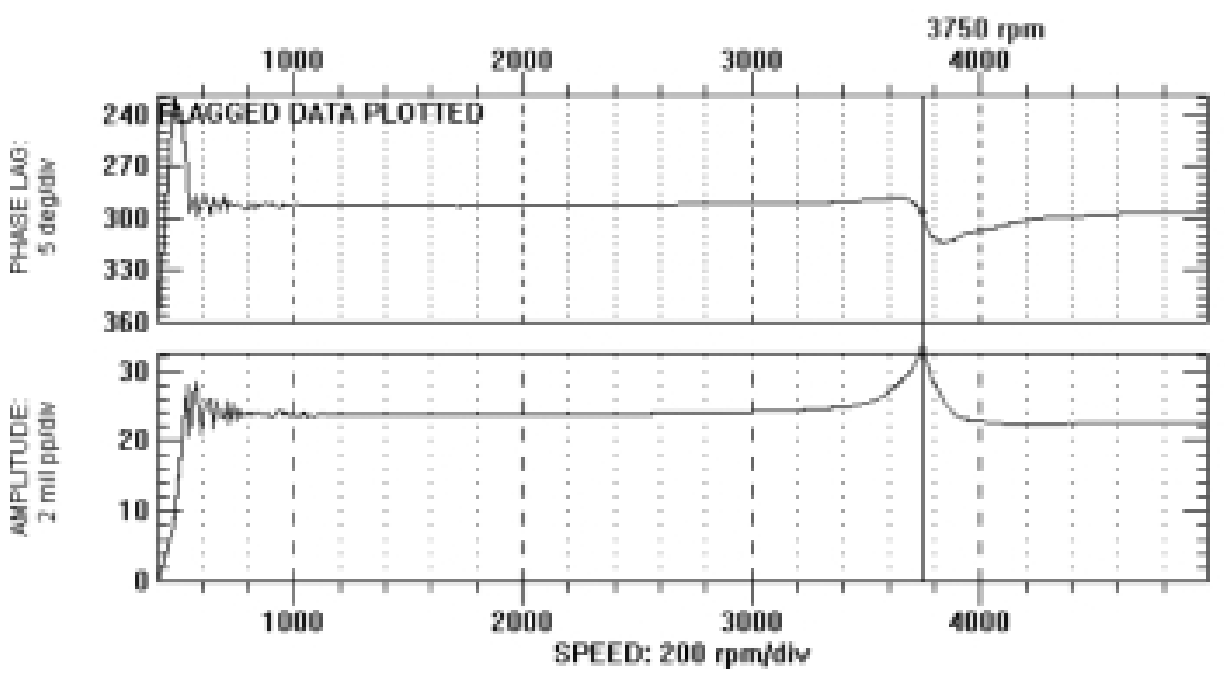

(a) Vertical direction

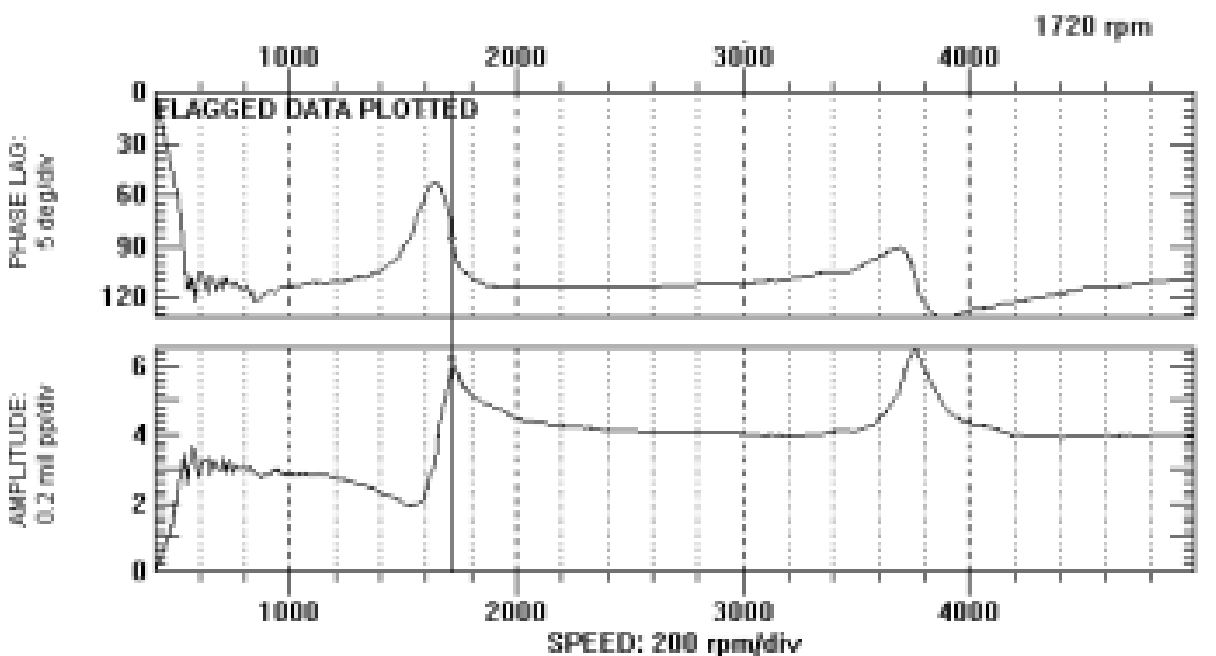

(b) Horizontal direction

Fig. 10. Bode plots of startup data for the 2 nd shaft with $4 \mathrm{~mm}$ notch crack with $8 \mathrm{~kg}$ vertical hanging side load.

and horizontal directions and their percentage change. The averaged critical speeds for the un-cracked rotor and the cracked rotors are also presented in the table for comparison.

\section{Conclusions}

Experimental results on the dynamic response of an overhung rotor with $4 \mathrm{~mm} v$-notch propagating transverse crack is presented. Since the machine history is important in fault detection in rotating machines, startup vibration signals of un-cracked and cracked shafts were presented in the form of Bode plots and Frequency Cascades for comparison. Steady state data for the un-cracked and cracked rotors were presented in the form of Frequency Waterfalls and orbits. The startup results showed that crack reduces the critical speed and increases the vibration amplitude of the rotor system and also excites $2 \mathrm{X}$ vibration harmonic. The steady state results showed that a propagating crack produces changes in vibration amplitudes of $1 \mathrm{X}$ and $2 \mathrm{X}$ harmonics and excites $3 \mathrm{X}$ harmonic at a later stage of crack propagation. During crack propagation, $1 \mathrm{X}$ 


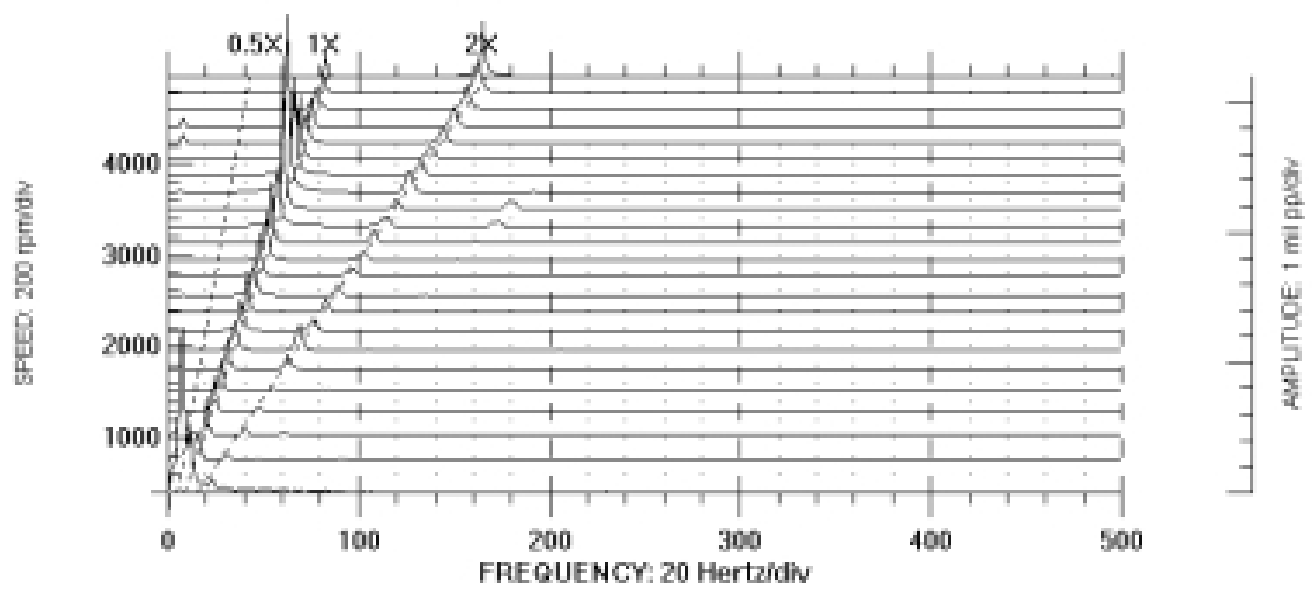

(a) Vertical direction

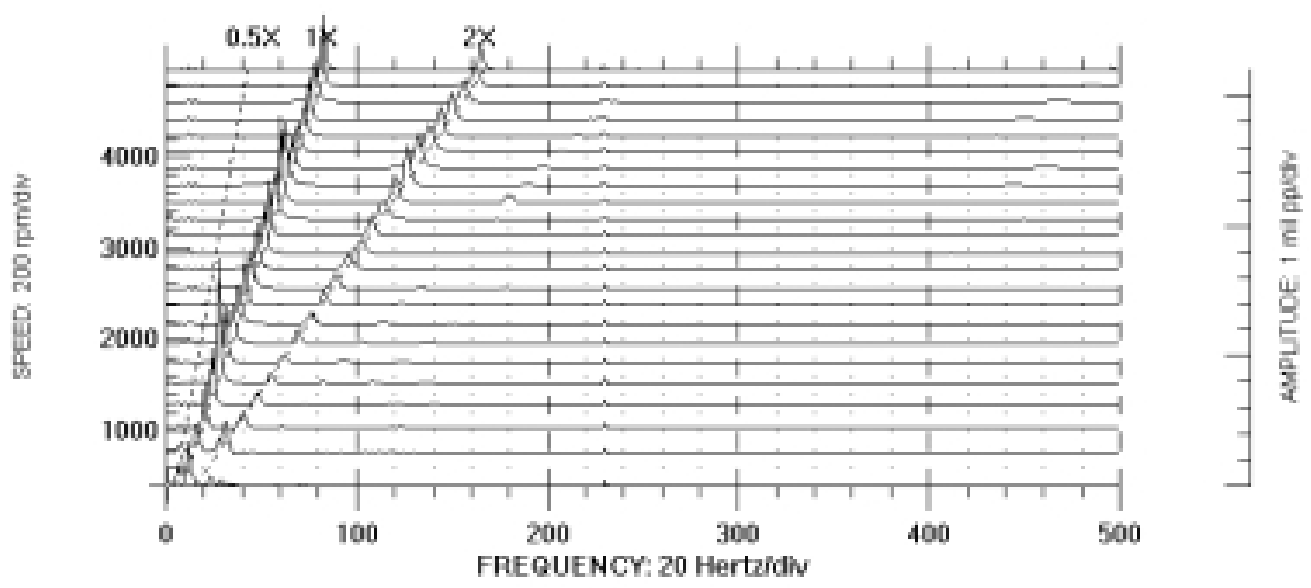

(b) Horizontal direction

Fig. 11. Frequency cascades of startup data for the 2 nd shaft with $4 \mathrm{~mm}$ notch crack and $8 \mathrm{~kg}$ vertical hanging side load.

amplitude may increase or decrease depending on the location of the crack while $2 \mathrm{X}$ amplitude always increases as the crack propagates. The steady state vibration signal of a propagating crack also produces a twoloop orbit. Changes in amplitudes of $1 \mathrm{X}$ and $2 \mathrm{X}$ vibration harmonics at a constant running speed is an important feature that distinguishes a propagating crack from imbalance and misalignment. These relative changes should be monitored and not their absolute values. The results obtained suggest that the dynamic response of an overhung rotor to a propagating crack is similar to the dynamic response of a simply supported rotor to a propagating crack. Further studies using mathematical modeling to quantify the rate of change in $2 \mathrm{X}$ vibration signal as related to the changing crack depth is recommended.

\section{Acknowledgement}

The authors appreciate the support of King Fahd University of Petroleum and Minerals, Dhahran, Saudi Arabia. The support of Dr. Don Bently of Bently Nevada Corporation, Minden-Nevada, USA is also acknowledged and appreciated.

\section{References}

[1] R. Gasch, A Survey of the Dynamic Behavior of a Simple Rotating Shaft with a Transverse Crack, Journal of Sound and Vibration 160(2) (1993), 313-332.

[2] B. Grabowski, The Vibrational Behavior of a Turbine Rotor Containing a Transverse Crack, Transactions of the ASME 102 (1980), 141-146. 


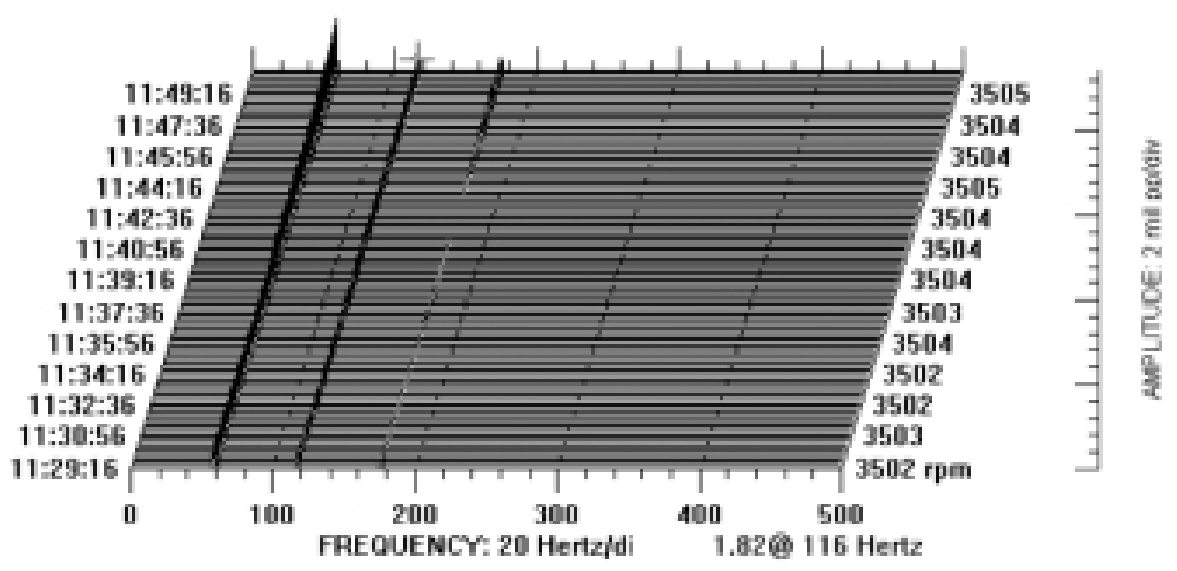

(a) Vertical direction

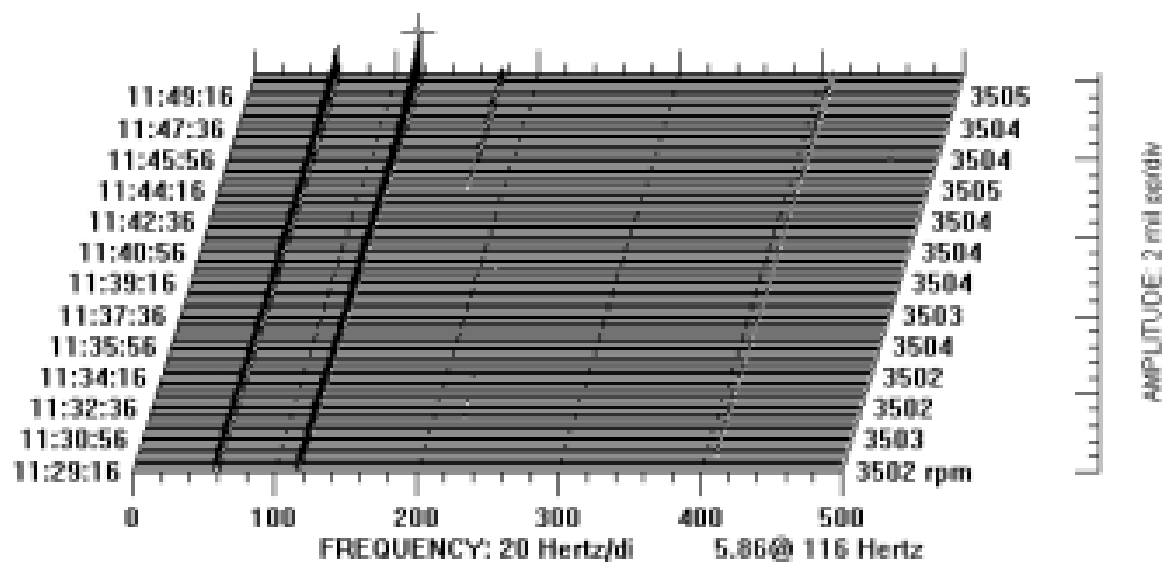

(b) Horizontal direction

Fig. 12. Frequency waterfalls of steady state data at $3500 \mathrm{rpm}$ for the 2 nd shaft with $4 \mathrm{~mm}$ notch crack with $8 \mathrm{~kg}$ vertical hanging side load.

[3] A.D. Dimarogonas and S.A. Paipetis, Analytical Methods in Rotor Dynamics, Applied Science Publishers, London, 1983.

[4] Imam, S.H. Azzaro, R.J. Bankert and J. Scheibel, Development of an On-Line Rotor Crack Detection and Monitoring System, Journal of Vibration, Acoustics, Stress, and Reliability in Design 111 (1989), 241-250.

[5] T. Inagaki, H. Kanki and S. Shiraki, Transverse Vibrations of a General Cracked Rotor Bearing System, Journal of Mechanical Design 104 (1982), 345-355.

[6] B.O. Dirr and B.K. Schmalhorst, Crack Depth Analysis of A Rotating Shaft by Vibration Measurements, 11th ASME Conference on Mechanical Vibration and Noise, Boston, 1987, pp. 607-614.

[7] I.W. Mayes and W.G.R. Davies, Analysis of the Response of a Multi-Rotor-Bearing System Containing a Transverse Crack in a Rotor, Journal of Vibration, Acoustics, Stress, and Reliability in Design 106 (1984), 139-145.

[8] D.E. Bently and R.F. Bosmans, Case Study of Shaft Crack Failure, Orbit, 1989
[9] J. Wauer, On the Dynamics of Cracked Rotors: A Literature Survey, Applied Mechanics Review 43(1) (1990), 13-17.

[10] J. Wauer, Modeling and Formulation of Equations of Motion for Cracked rotating Shafts, International Journal of Solids Structures 26(8) (1990), 901-914.

[11] K.R. Collins, R.H. Plaut, C.E. Via and J. Wauer, Detection of Cracks in Rotating Timoshenko Shafts using Axial Impulses, Transactions of the ASME 113 (1991), 74-78.

[12] G. Diana, N. Bachschmid and F. Angeli, An On-Line Crack Detection Method for Turbogenerator Rotors, Proceedings of International Conference on Rotordynamics, Tokyo, 1986, pp. 385-390.

[13] A.D. Damarogonas and C.A. Papadopoulas, Vibration of Cracked Shaft in Bending, Journal of Sound and Vibration 91 (1983), 583-593.

[14] G. Meng and E.J. Hahn, Dynamic Response of a Cracked Rotor With Some Comments on Crack Detection, Journal of Engineering for Gas Turbine 119 (1997), 447-455. 


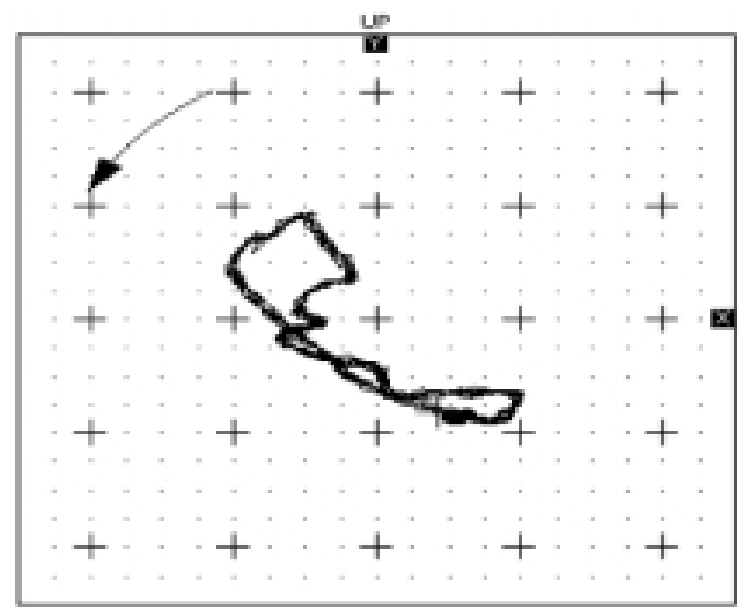

o.s maldin

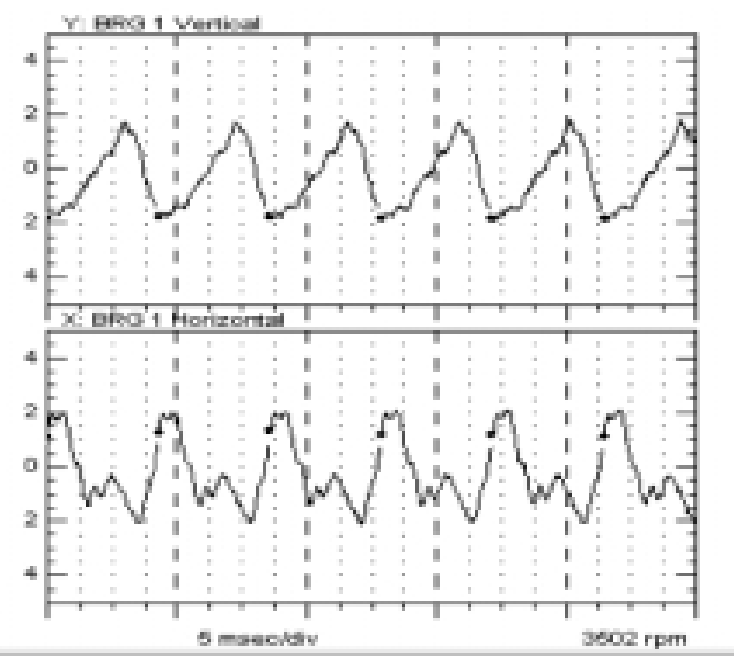

$3002 \mathrm{rpm}$

(a) Before crack propagation

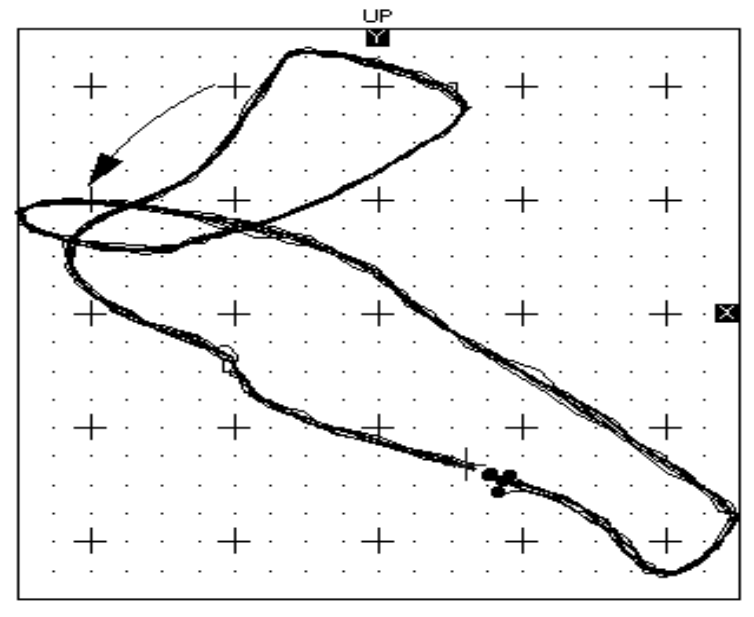

0.5 mil/div

ROTATION: $\times$ TOY (CON)

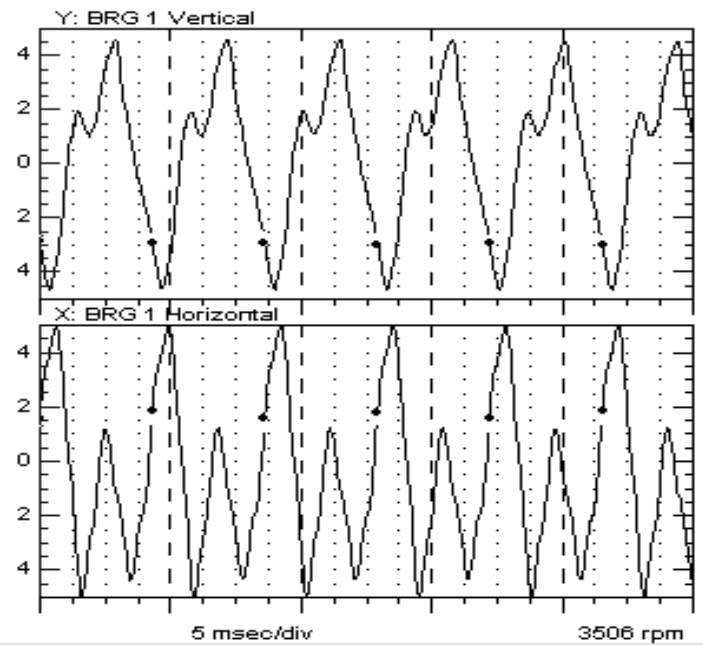

(b) During crack propagation.

Fig. 13. Orbit of steady state data at $3500 \mathrm{rpm}$ for the $2 \mathrm{nd}$ shaft with $4 \mathrm{~mm}$ notch crack and $8 \mathrm{~kg}$ vertical hanging side load during crack propagation.

[15] M.-C. Wu and S.-S. Huang, In-Plane Vibration and Crack Detection of a Rotating Shaft-Disk Containing a Transverse Crack, Journal of Vibration and Acoustics 120 (1998), 551555.

[16] G.T. Zheng, Vibration of a Rotor System with a Switching
Crack and Detection of the Crack, Journal of Engineering for Gas Turbine 120 (1998), 149-154.

[17] L.R.K. Nilson, On the Vibration Behavior of A Cracked Rotor IFToMM Rotordynamics Problems in Power Plants Conference Proceedings, Rome, Sep 1982, pp. 512-524. 

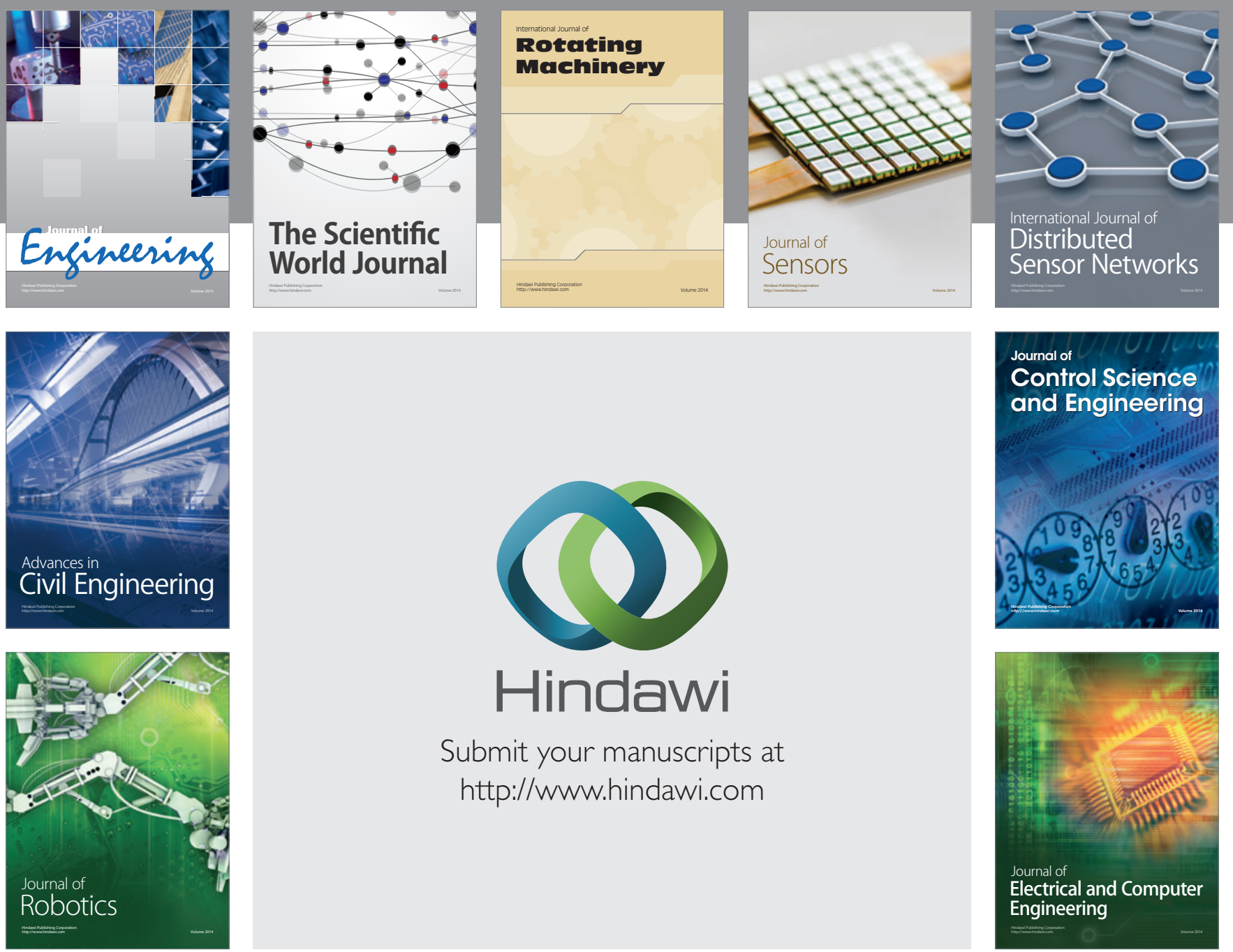

Submit your manuscripts at

http://www.hindawi.com
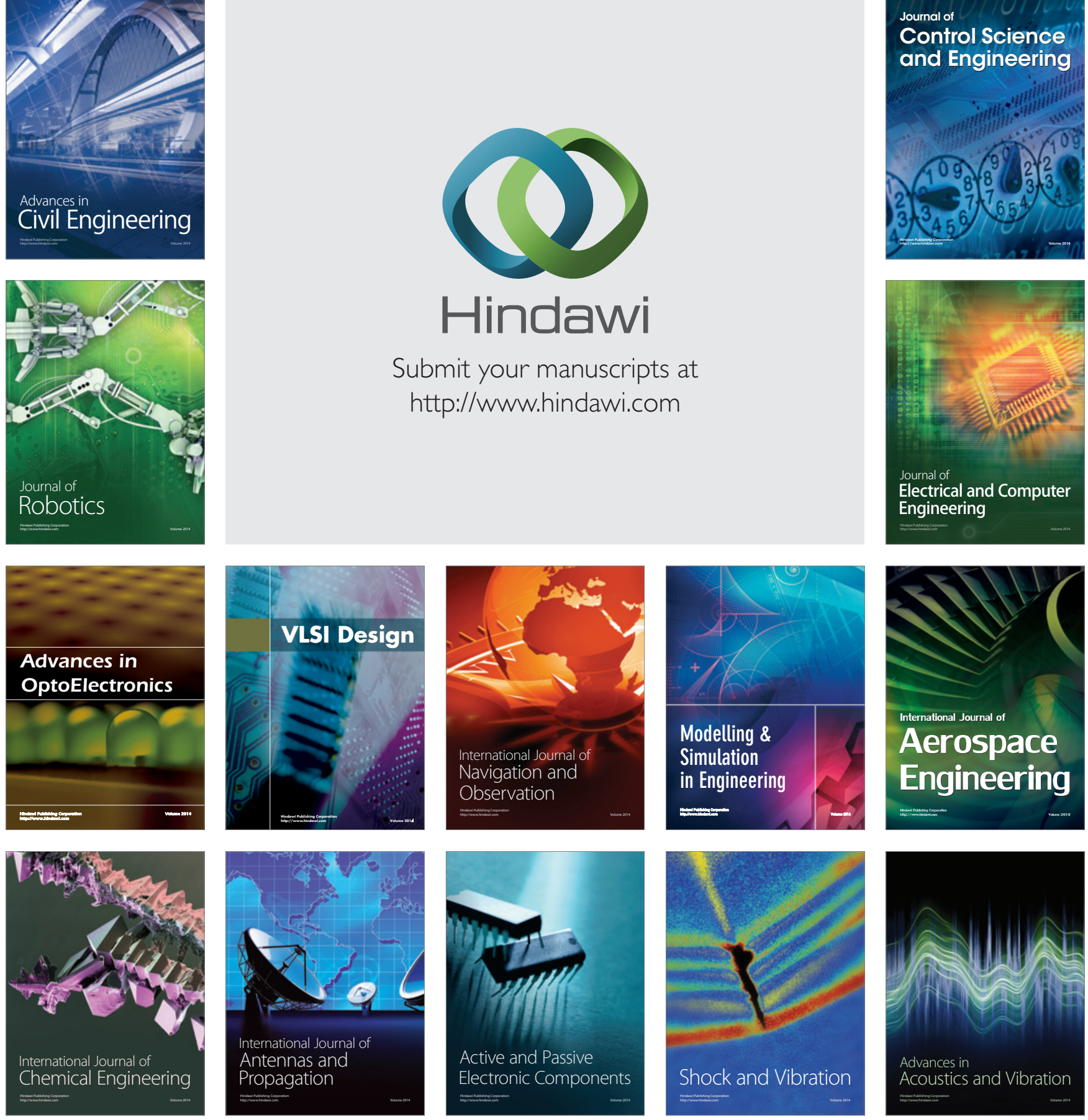